\title{
Correction to: Tourist Behavior Predicts Reactions of Macaques (Macaca fascicularis and M. nemestrina) at Sepilok Orang-Utan Rehabilitation Centre, Sabah, Malaysia
}

\author{
Lauren J. Gilhooly ${ }^{1,2,3}$ D $\cdot$ Richard Burger $^{3} \cdot$ Symphorosa Sipangkui ${ }^{4}$. \\ Ian C. Colquhoun ${ }^{1,2}$
}

Published online: 4 May 2021

(C) Springer Science+Business Media, LLC, part of Springer Nature 2021

\section{Correction to: International Journal of Primatology. https://doi.org/10.1007/s10764-021-00205-7}

The original version of this article unfortunately contained a mistake in the authorgroup section. Author Symphorosa Sipangkui's first name was inadvertently spelled as "Sympharosa".

The original article has been corrected.

The online version of the original article can be found at https://doi.org/10.1007/s10764-021-00205-7

Lauren J. Gilhooly

laurengilhooly19@gmail.com

1 Department of Anthropology, University of Western Ontario, London, ON, Canada

2 Centre for Environment and Sustainability, University of Western Ontario, London, ON, Canada

3 Danau Girang Field Centre, Kota Kinabalu, Sabah, Malaysia

4 Sabah Wildlife Department, Kota Kinabalu, Sabah, Malaysia 